\title{
As tramas do cuidado nas condições crônicas de saúde na infância e adolescência
}

\author{
Pathways of care in chronic childhood and adolescent \\ health conditions
}

\author{
Los entresijos de los cuidados en condiciones crónicas de salud \\ durante la infancia y adolescencia
}

TESSITURAS DO CUIDADO: AS CONDIÇÕES CRÔNICAS DE SAÚDE NA INFÂNCIA E ADOLESCÊNCIA. Alves CA. Rio de Janeiro: Editora Fiocruz; 2016. 214 p. (Coleção Criança, Mulher e Saúde). ISBN 978-85-7541-480-4

doi: 10.1590/0102-311X00161117

Camila Aloísio Alves, psicóloga e sanitarista, teve o adoecimento crônico infantil como foco de estudo e trabalho no mestrado e no doutorado, sendo que, deste último, emana o presente livro. Inquietada por "compreender as possibilidades de se produzir um projeto de vida com e apesar do adoecimento crônico" (p. 14), toma o cuidado como categoria central de seu estudo. Indaga como aquele se expressa nas ações dos profissionais de saúde e também como tais ações refletem na vida de crianças e adolescentes nessa condição, bem como na de suas famílias.

Empregando a alegoria dos fios (profissionais da saúde, crianças e adolescentes e suas famílias que participaram do estudo) e das tramas (interações, sociais, redes de apoio e produção de cuidado), a autora visa a dar a conhecer, ao longo de oito capítulos, os elementos, os desafios e as possibilidades inscritos no enredo e na tessitura do cuidado nessa condição de adoecimento. Torna-se, assim, leitura recomendada a todo profissional de saúde que vivencie a assistência a pessoas em condições crônicas, especialmente crianças e adolescentes. Oferece, ainda, importantes subsídios de reflexão para elaboradores de políticas de atenção a essas pessoas, pois expõe pontos de tensão do cuidado, particularmente diante do imperativo de articular a prática assistencial em rede, de forma a garantir sua continuidade e o acolhimento das novas necessidades surgidas ao longo do tempo. No dizer da autora, "os elementos - tecnologia, sobrevida e cuidado - produzem influência recíproca, gerando movimentos na forma de prover o cuidado" (p. 118), movimento este que nem sempre se mostra efetivo.

Tomando como ponto de partida de sua reflexão as mudanças atuais no campo da saúde, bem como as transformações ocorridas no perfil epidemiológico nas últimas décadas no Brasil, que põem as condições crônicas como grande desafio no ordenamento de saberes e práticas, a autora tematiza os avanços científicos e tecnológicos que têm possibilitado, dentre outros resultados, maior sobrevida de pessoas com adoecimentos crônicos. Essa realidade é particularmente importante em seus efeitos na área da neonatologia e pediatria, visto que, daí, emergem crianças e adolescentes dependentes de tecnologias e de cuidados especializados para sustentação e manutenção de suas vidas ao longo do tempo. No dizer de um dos profissionais entrevistados, "a gente está produzindo essas crianças na UTI” (p. 121). 
A autora enfatiza que "a cronicidade tanto coloca o profissional diante da tecnologia e do seu manejo como o convoca para o aprendizado de habilidades que o tornem capaz de lidar com outras complexidades, relacionadas à realidade de vida dos pacientes" (p. 125). Assim, são necessárias também habilidades relacionais e emocionais que, ao longo do estudo, percebemos serem ainda pouco desenvolvidas e/ ou valorizadas na formação do profissional, de modo que possa melhor acolher as necessidades das famílias que precisarão arranjar-se no seu cotidiano para produzir os cuidados continuados e/ou permanentes que as crianças e adolescentes requerem.

Por eleger como cenário do estudo duas instituições hospitalares voltadas, dentre outras, a assistência de crianças e adolescentes com condição crônica severa, a autora vai buscar os elementos constituidores de saberes e práticas, ainda em construção tensionada no dia a dia dos profissionais de saúde. Não tendo por objetivo comparar as instituições, dá relevo aos modos particulares de organização e oferta das práticas profissionais, tanto em relação à posição que cada uma ocupa na rede assistencial, quanto às características quantitativas e qualitativas das equipes que aí atuam e na sua interação.

Emanado do campo acadêmico, visto tratarse, originalmente, de tese de doutorado, o estudo segue o rigor científico de uma pesquisa, mantendo a sensibilidade necessária na descrição e na análise, conferindo relevo ao humano e explicitando sentimentos, vulnerabilidades e possibilidades vividas pelos participantes do estudo - de modo especial os profissionais de saúde, mas também as crianças, adolescentes e suas famílias.

Tendo a observação e entrevista como estratégias privilegiadas para apreender as práticas profissionais e os saberes que as constituem, percebemos que, às vezes, o olhar da pesquisadora se aproxima do dos profissionais, adentrandolhes a lógica própria, de maneira mais empática. Em outras, achega-se mais à compreensão das vivências das crianças e dos adolescentes adoecidos e suas famílias e, nessa proximidade, acolhe seus sofrimentos, dificuldades e as possibilidades de amenizá-los pela constituição de práticas profissionais mais afetivas e efetivas.

Ao longo do estudo, descrevendo o cotidiano dos profissionais, tramado por um entretecer de acontecimentos, sentimentos, presenças e ausências, deixa ver o movimento próprio que, no seu conjunto como "equipe", imprime à assistência. Ao mesmo tempo, pela aproximação e distanciamento de seu foco de atenção, observação e análise, a autora consegue mostrar as relações do microcosmo de atuação de cada profissional com o todo dessa assistência prestada na instituição. Nesse movimento, ensaia mostrar como essas práticas repercutem na vida das crianças, dos adolescentes e de suas famílias, facilitando-lhes ou dificultando-lhes o cuidado e o viver.

É importante salientar que, ao trazer como cenário do estudo duas instituições de saúde de alta complexidade na assistência à criança e adolescente com adoecimentos crônicos e dependentes de tecnologias, a autora mostra, no nível mais amplo, as afetações que decisões gerenciais e políticas institucionais têm no modo como os profissionais organizam e oferecem suas práticas assistenciais, reverberando, de maneira intensa, no microcosmo da vida das famílias. No entanto, ainda não percebemos a valorização da lógica própria da organização do microcosmo da família para o cuidado como forma de consubstanciar e direcionar tanto as práticas profissionais quanto as políticas, visando a torná-las mais amistosas ao cuidado integral. Sobre isso, a autora afirma que as condições crônicas de saúde da criança e dos adolescentes "convocam os sujeitos e a própria política de saúde a repesar o modo como a atenção em saúde é provida, como os sujeitos nela interagem, como os profissionais são formados e como a dinâmica do cuidado se estrutura na rede de serviços de saúde. [Afinal], cuidar de crianças e adolescentes crônicos exige entender e atuar de forma integral, o que só se alcança em um campo de trocas e compartilhamentos horizontais nos serviços e entre os atores sociais. (...) Além de ser um exercício de parceria e troca para profissionais e familiares, o cuidado compreendido nessa perspectiva articulada e integrada contribui para que a assistência provida seja menos permeada por con- 
flitos e, ao mesmo tempo, mais aberta à construção de saberes e conhecimentos que respeitem o universo de referência do paciente" (p. 199-200).

Nesse sentido, entendemos que o estudo traz contribuições valiosas ao eleger seu foco de observação, privilegiadamente, para os modos de organização e oferta das práticas profissionais na internalidade do hospital, dando-lhes a conhecer, em suas miudezas, dificuldades e características próprias. No entanto, deixa com pouca evidência a afetação que tais práticas produzem na vida cotidiana das crianças e dos adolescentes, bem como os muitos custos para a família que cuida, contínua e permanentemente, de seus filhos dependentes de tecnologias. É necessário reforçar que tal aparato do cuidar, embora com- plexo, dificilmente é sustentado e mantido pela rede de saúde mais ampliada. Assim, há que se intensificar estudos que tragam o dia a dia dessas famílias, tendo por foco sua própria perspectiva de vida e cuidado, tensionando saberes, aparatos tecnológicos e práticas profissionais institucionalizados e aqueles que são transferidos para o ambiente doméstico, visto que a criança e/ou adolescente dependentes de tecnologias exigem cuidado profissionalizado, não raro, a ser desenvolvido pela família.

Roseney Bellato 1

1 Universidade Federal de Mato Grosso, Cuiabá, Brasil. roseneybellato@gmail.com 